\title{
Integrating Process and Factor Understanding of Environmental Innovation by Water Utilities
}

\author{
Marc Spiller • Brian S. McIntosh • Roger A. F. Seaton • \\ Paul J. Jeffrey
}

Received: 4 August 2014 / Accepted: 9 January 2015 /

Published online: 30 January 2015

(C) The Author(s) 2015. This article is published with open access at Springerlink.com

\begin{abstract}
Innovations in technology and organisations are central to enabling the water sector to adapt to major environmental changes such as climate change, land degradation or drinking water pollution. While there are literatures on innovation as a process and on the factors that influence it, there is little research that integrates these. Development of such an integrated understanding of innovation is central to understanding how policy makers and organisations can stimulate and direct environmental innovation. In the research reported here a framework is developed that enables such an integrated analysis of innovation process and factors. From research interviews and the literature twenty factors were identified that affect the five stages of the environmental innovation process in English and Welsh water utilities. The environmental innovations investigated are measures taken by water utilities to reduce or prevent pollution in drinking water catchments rather than technical measures to treat water. These Source Control Interventions are similar to other environmental innovations, such as ecosystem and species conservation, in that they emphasise the mix of technology, management and engagement with multiple actors. Results show that in water utilities direct performance regulation and regulation that raises awareness of a 'performance' gap as a 'problem' can stimulate innovation, but only under particular organisational, natural physical and regulatory conditions. The integrated framework also suggests that while flexible or framework legislation (e.g. Water Framework Directive) does not stimulate innovation in itself, it has shaped the option spaces and characteristics of innovations selected towards source control instead of technical end-ofpipe solutions.
\end{abstract}

\footnotetext{
M. Spiller $(\bowtie)$

Wageningen University, Bornse Weilanden 9, P.O. Box 17, 6700 AA, Wageningen, The Netherlands e-mail: marc.spiller@wur.nl
}

\section{B. S. McIntosh}

International Water Centre, Brisbane, Australia

R. A. F. Seaton - P. J. Jeffrey

Cranfield Water Science Institute, Cranfield University, Bedfordshire, UK

R. A. F. Seaton

Seaton Associates, Suffolk, Southwold, UK 
Keywords Innovation process $\cdot$ Factors $\cdot$ Catchment management $\cdot$ Water utilities

\section{Introduction}

It is now widely recognised that the implementation of sustainable urban water management needs an emphasis on, inter alia, water resource protection, water efficiency and reuse (Brown and Farrelly 2009; Daigger 2012). To achieve this, water utilities not only need to innovate in relation to the adoption of new technologies (Daigger 2012; Kujawa-Roeleveld and Zeeman 2006; Verstraete and Vlaeminck 2011), but also with respect to non-technical approaches including catchment management and the management of decentralised water and wastewater services (Daigger 2012; Dolan et al. 2014). In order for regulation and utility management to influence innovation pathways it is essential to understand the processes and the factors that affect the selection of types of innovations of most relevance to water and sewerage utilities.

Whilst the need to integrate an understanding of the processes of innovation and the factors that affect innovation has been recognised (del Rio Gonzalez 2009), research that combines the two is limited. The integration of decision processes with the relevant influential factors offers the opportunity to identify how both relate to each other and to innovation outcomes. Such a novel integration potentially offers insight into how water utility innovation can be stimulated and managed. This insight may reveal at which stage of an innovation process which factors have the most significant effect and how the same factors may lead to different innovation outcomes at these different stages.

The aim of this paper is to develop such an integrated conceptual framework. The conceptual framework is applied to a new class of environmental innovations of interest to water utilities and urban water management - Source Control Interventions or SCIs (Spiller et al. 2013a). By doing so, this paper will show the ways in which the integration of process and factors can contribute to a better understanding of:

- how to foster 'problem' identification in water utilities and thereby the initiation of innovation,

- how to influence the choice of specific types of innovation, such as source control versus end-of-pipe technologies,

- how to encourage a wider adoption of environmental innovations, particularly SCIs, within and across water utilities.

In the first part of this paper the integrated process and factor framework is developed. Then it is applied to the privatised water utilities in England and Wales (E\&W) and the innovation processes surrounding SCIs. These SCIs are characterised as activities by water utilities to control pollution of water resources at source (Spiller et al. 2013a). As the adoption of SCIs depends on the characteristics of the catchment, the study investigates the effect of natural and physical environment factors on the innovation adoption process. From a general innovation perspective, the choice of SCIs as a theme will also demonstrate the complexities of environmental innovation which comprise a mix of changes in technological and management practice, and involve engagement with multiple actors outside the organisational boundaries of water utilities. This differs from end of pipe (treatment) innovation which can often be realized through technological and scientific changes that are mainly designed and implemented under the direct control of the water utility. 


\section{Conceptual Framework}

The conceptual framework comprises three key elements (Fig. 1): a) the 5 stage overall organisational model of the innovation process, b) the intra-stage process of diagnosis and evaluation and choice and c) the set of factors that influence each stage of the process.

\subsection{The Innovation Process}

Spiller et al. $(2012,2013 b)$ reviewed a range of organisational innovation processes described in the literature. These processes commonly start with the 'realisation of a need for change' and progress to the 'use and implementation' of the innovation finally selected. Spiller et al. (2012, 2013b) and more recently Karakaya et al. (2014) conclude that the well-known innovation model of Rogers'(2003) is a useful starting point for conceptualising the structure of environmental innovation processes at the organisational scale. Rogers' model is divided into five sequential stages beginning with Agenda Setting (Fig. 1a). The outcome of this stage is the realisation of a need for change as a consequence of having recognised a 'performance gap' or the 'deviation of a current state in relation to a desired objective or aspiration level' (Cohen and Levinthal 1990; Teece et al. 1997).

The second stage involves generating and choosing amongst possible options. While Rogers (2003) calls this 'Matching', we term this 'Choice Between Alternatives' so as to emphasise that possible options are accepted or rejected. In the next stage, options are redefined or redesigned to fit their specific context/needs. Alternatively, elements or procedures of the organisation itself may be restructured to better exploit or use the innovation

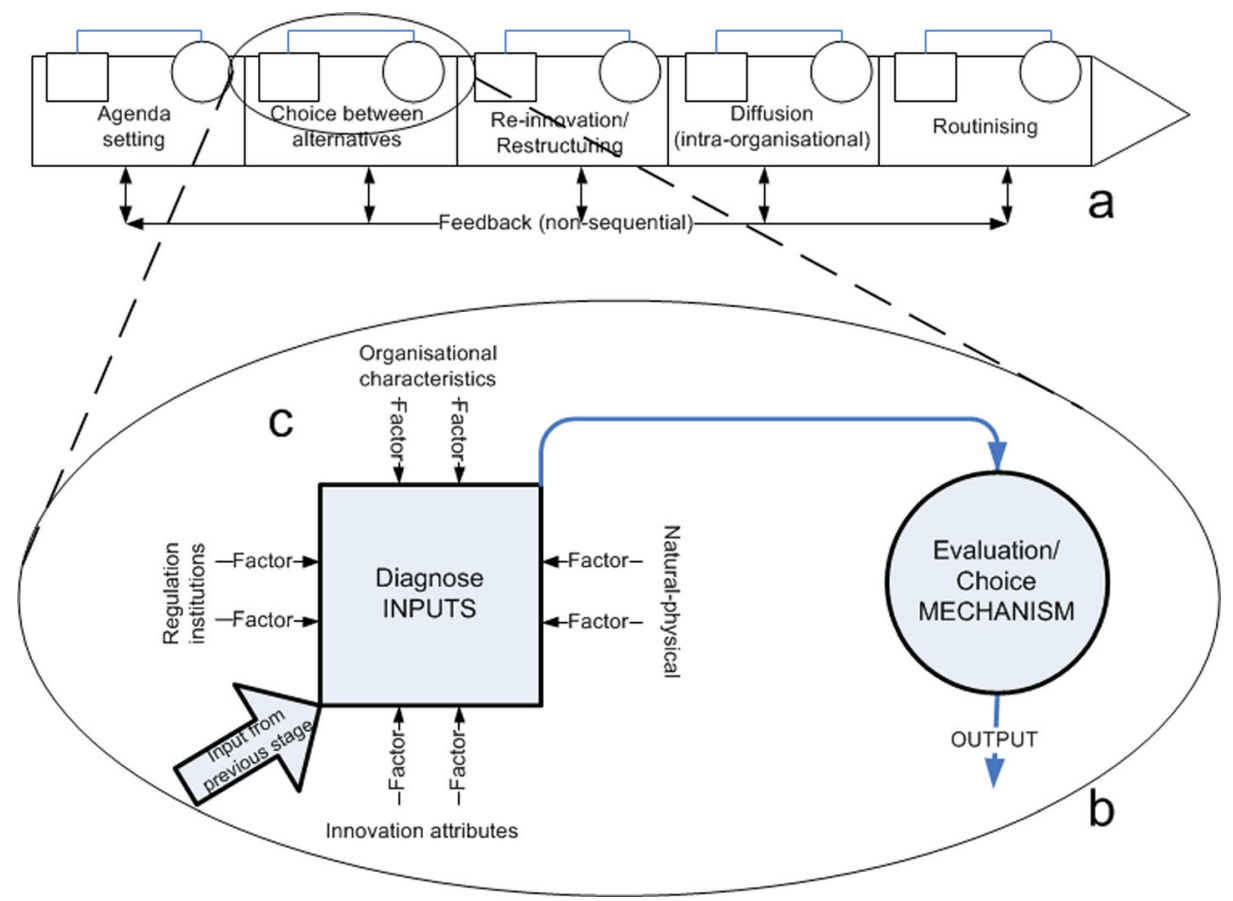

Fig. 1 The framework used to conceptualise innovation in this research: a five stage process model adapted from Rogers (2003), b intra process decision stages $\mathbf{c}$ factors in four domains that affect the innovation process 
concerned. The 'Diffusion' stage involves actors in the organisation deciding on whether and where to diffuse the innovation. Finally, 'Routinisation' is achieved when the innovation is no longer considered novel, but rather, it's procedures and protocols become part of the everyday way things are done in an organisation.

\subsection{Diagnosis and Evaluation}

The process of innovation is also one of decision making (Du et al. 2007; Heerkens 2006). Indeed, models of analytical decision making and innovation processes share a common ancestry (Simon 1997) and each of Rogers' (2003) innovation stages involve more or less explicit decisions. Assumptions and boundary conditions that influence the innovation process can be derived from theories and practice of decision making. We will focus on decision making as a process of 'Diagnosis' or 'problem identification' and 'Evaluation'. By examining these 'Diagnosis' and 'Evaluation' routines it is possible to distinguish the interaction between factors and the mechanisms for making trade-offs between these factors (i.e. Evaluation) at every innovation stage (Fig. 1b).

Mintzberg and Raisinghani (1976) in their seminal work propose that in 'Diagnosis' data are gathered and the issue is better understood. In 'Evaluation' the 'best' solution is arrived at through the three modes of 'Judgement', 'Bargaining' or 'Analysis'. In the 'Judgement' stage an individual makes a choice of their own; 'Bargaining' is the selection made by a group of decision makers; while 'Analysis' involves the formal evaluation of technical performance indicators. Since Mintzberg and Raisinghani (1976) do not break down the decision making process into stages, where 'Diagnosis' and 'Evaluation' take place cannot be identfied. However, as is evident from Rogers' (2003), each of the five stages will involve one or more decisions. The evaluation of a performance gap or the balancing of multiple criteria in the first and second stages of the innovation process are examples of an analytical decision routine. In the third stage, multiple decisions are involved to mutually adapt both the innovation and organisation to each other, usually involving organisational learning. Finally, decisions will be made about where to migrate the innovation (i.e. diffuse), before the innovation evolves into every day pratice.

\subsection{Factors Influencing Innovation}

To structure the factors that influence each stage of the innovation process we derived four 'domains' from the literature: regulation \& institutions, natural physical factors, characteristics of the innovator, and innovation attributes (for a similar classification see del Rio Gonzalez 2009 - Fig. 1c).

\subsubsection{Institutional Environment}

The characteristics of the institutional environment will influence the innovation process through regulation (Horbach 2008). Porter and van der Linde's (1995) argue that regulation that requires organisations to gather information can result in improved environmental performance by raising their awareness of their own performance. They argue that 'light touch' regulation can be addressed by end of pipe solutions without innovation, while stricter regulation may lead to more radical changes. Similarly, in the EU, direct regulation that defines and enforces specific standards is successful in promoting technical change by setting performance targets and creating a 'performance gap' (Maria 2005). Contrary to this, Sharma (2001) found that direct environmental regulation is important for raising awareness and 
setting minimum benchmarks, but other external and internal factors are more important (e.g. shareholders, values, markets). Other evidence suggest that the adoption of end of pipe technologies rather than process innovations is encouraged by direct regulation (Georg 1994). Similarly, indirect or flexible regulation which grants organisations the freedom of choice on how to achieve goals by setting ambitious frameworks for change is a more effective means of influencing organisational change (Cleff and Rennings 1999; Majumdar and Marcus 2001). Indeed, a mix of indirect and direct regulation is considered to be the optimal approach to environmental regulation (Harrison 1998).

Another important means to stimulate innovation is competition in markets (Cleff and Rennings 1999). In the context of the monopolistic water utilities, regulation should encourage competition to generate efficiency gains through innovation (Cave 2009). While efficiency has increased in water utilities in E\&W, economic regulation is still considered to be a barrier to change towards more sustainable practice by inter alia encouraging short term investments and favouring investments that increase the book value of the utility (Cashman and Lewis 2007; Thomas and Ford 2005). Furthermore, Barrett and Wallace (2011) argue that to achieve socially desirable objectives of utilities a higher degree of public control and regulation is required. Contrary to this Lieberherr and Truffer (2014) suggest that private and public-private water companies are likely to generate more innovative capabilities, although there is no clear cut relationship between governance modes and innovation.

\subsubsection{Natural Physical}

In the literature little attention has been paid to the influence of the natural-physical environment on innovation pathways. A few authors discuss whether the natural-physical environment can be a crucial factor for successful adoption of innovations, especially when organisations are concerned with natural resources management (Ormrod 1990). For water utilities, natural-physical conditions have been shown to affect innovation pathways of water utilities in the UK (Cave 2009; Spiller et al. 2009) and implementation of water saving campaigns in Italy (Romano et al. 2014).

\subsubsection{Characteristics of the Innovator}

The 'Characteristics of the innovator' that can influence the innovation process include organisational size, structure, normative beliefs, investment in innovation activities and knowledge. Different organisational structures affect the capability of organisations to innovate because they create different preconditions for the communication and development of ideas, knowledge and inventions (Burns and Stalker 1968). Attitudes towards innovations and framing of innovations may influence adoption, through an implicit preference for particular types of alternatives (Buysse and Verbeke 2003; Sharma 2000). Many authors agree that the ability to accumulate, use and transfer knowledge is crucial to the development and adoption of innovations (Cohen and Levinthal 1990; Horbach 2008; Rothwell 1992). For the water utilities it is proposed that obstacles to innovation are grounded in pre-existing organisational preferences and that incremental innovation are a consequence of long asset lifetimes (Marlow et al. 2013). Similarly, the privatised water utilities in E\&W have tended to give preference to established engineering solutions, are risk averse and more likely to carry out incremental innovation rather than radical changes (Cave 2009; Lieberherr and Truffer 2014; Thomas and Ford 2005). 


\subsubsection{Innovation Attributes}

The 'Innovation attributes' or 'characteristics of the innovation' - such as ease of trialling, ease of detecting and measuring outcomes, and the compatibility of the innovation with existing organisational knowledge, have been found to affect the rate of adoption of innovations by organisations i.e. the number of innovation adopted over a time interval (Rogers 2003). This rate is higher when the innovation provides a relative advantage (e.g. in terms of costs or environmental impact (Rennings 2000)), is compatible with existing organisational capabilities, is easy to trial and outcomes are easily observed. Complexity of the innovation is negatively related to adoption (Rogers 2003). SCIs are seen as uncertain and long term which makes the outcome of SCIs difficult to trial and observe (Spiller et al. 2013b). This is by no means a unique feature of SCIs, but rather any innovation in the water systems is likely to be multifaceted and difficult to predict (Marlow et al. 2013; Spiller et al. 2015). Finally, SCIs are incompatible with the polluter pays principle which has been enforced in water sector economic regulations in E\&W (Brouwer et al. 2003).

\section{Methodology}

\subsection{Interviews}

Data was gathered during 2009 using semi-structured interviews with 21 individuals from each of the 10 English and Welsh water and sewerage utilities (the entire population of utilities). The precondition for selection for an interview was that individuals had some formal responsibility for raw water quality or catchment management. At least two people from each water utility were interviewed to reduce the chances of idiosyncratic response. The aggregated responses from individuals are regarded as representing the viewpoint of the utility. All interviews were recorded and transcribed.

The analysis employed coding of the interview transcriptions (Strauss and Corbin 1998). Coding breaks down the text into discreet parts and subsequently collates related concepts into broader categories. Descriptive coding was used to identify factors that influence innovation (Miles and Huberman 1994). In this method the meaning of the text excerpt is summarised and each code is given a label that, where possible, is directly derived from the text. When a causal relationship was expressed by the interviewee, the related text was coded as a 'factor' influencing the innovation process. In other words, the text was classified as a 'factor' if the interviewee indicated that aspects such as costs, assets, land use or any other feature influenced their decision. The factors were populated through several iterations of this process and until no further observations were evident.

\subsection{Linking Interview Data to Process Stages}

More than 500 pages of interview text were coded to identify content associated with each of the five stages of the innovation process model. Text was considered to provide evidence for a process stage when the following features were detected:

Agenda Setting: Reference or statement describing the identification of a problem or issues.

Choice between Alternatives: Reference to alternatives to resolve the problem identified. 
Re-innovation: Reference to design of the innovation or alternatively adaptation of the organisation to the innovation.

Diffusion: Reference to further adoption of an intervention within the organisation.

Routinisation: Reference to intervention as a standard response mechanism embedded in organisational practice

For the Routinisation stage little data was available. This is a consequence of the research design which was based on an analysis of utilities at about the same time. It was impractical to undertake a longitudinal activity to properly study this phase.

\subsubsection{Proximity Analysis}

After the text was coded a proximity analysis was applied in which the text coded under both factor stage and the innovation stage was identified; in other words the text was identified that referred to factors and process stages together. Results from this analysis indicated where factors from each domain affect the innovation process. The matrix coding function in the NVivo 8 software facilitated this assessment. It resulted in a count of concurrency of text coded as factor and as a particular process stage, which was taken to indicate the importance of a particular factor in a specific process stage.

\section{Results and Discussion}

In this section it is shown how factors from the different domains influence each stage of the innovation process using the conceptual framework developed earlier. The frequency count of factors is indicated in the text in brackets and in the figures behind the arrows (Fig. 2, 3, and 4). The factors found to affect innovation are described in Box 1.

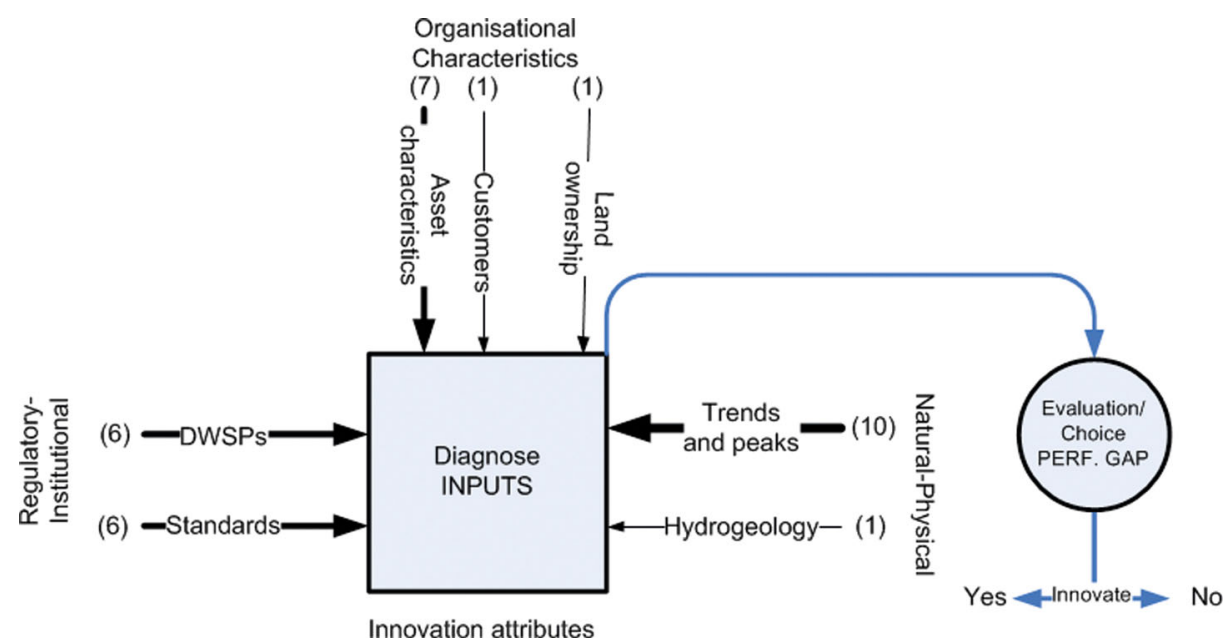

Fig. 2 'Agenda Setting' process and the factors influencing the process (the count of factor occurrence displayed in brackets after arrow; 10 is the highest score possible due to sample size of 10 water utilities) 


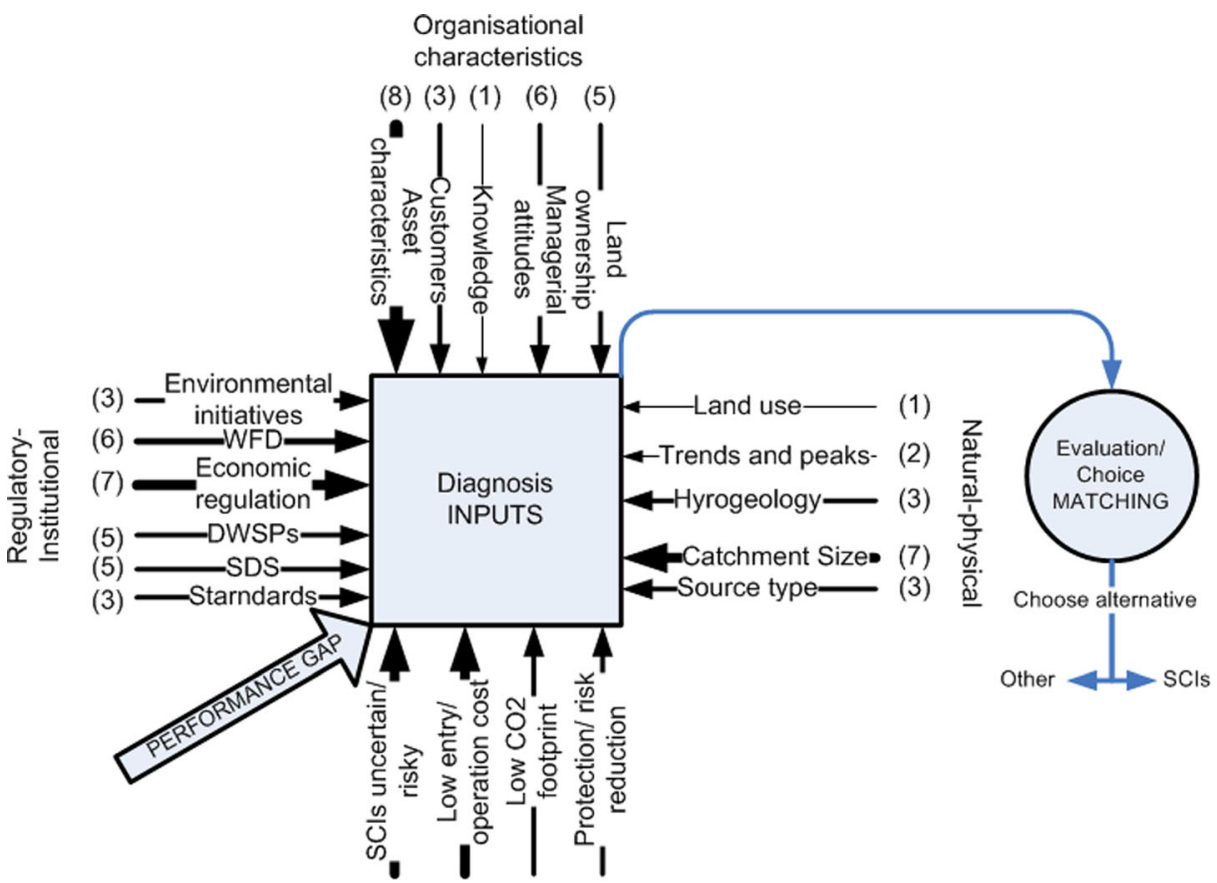

(8) (8) (5) (5)

Innovation attributes

Fig. 3 The 'Choice between Alternatives' process and the factors of influence (recurrence of factor displayed in brackets after arrow; 10 is the highest score possible due to sample size of 10 water utilities)

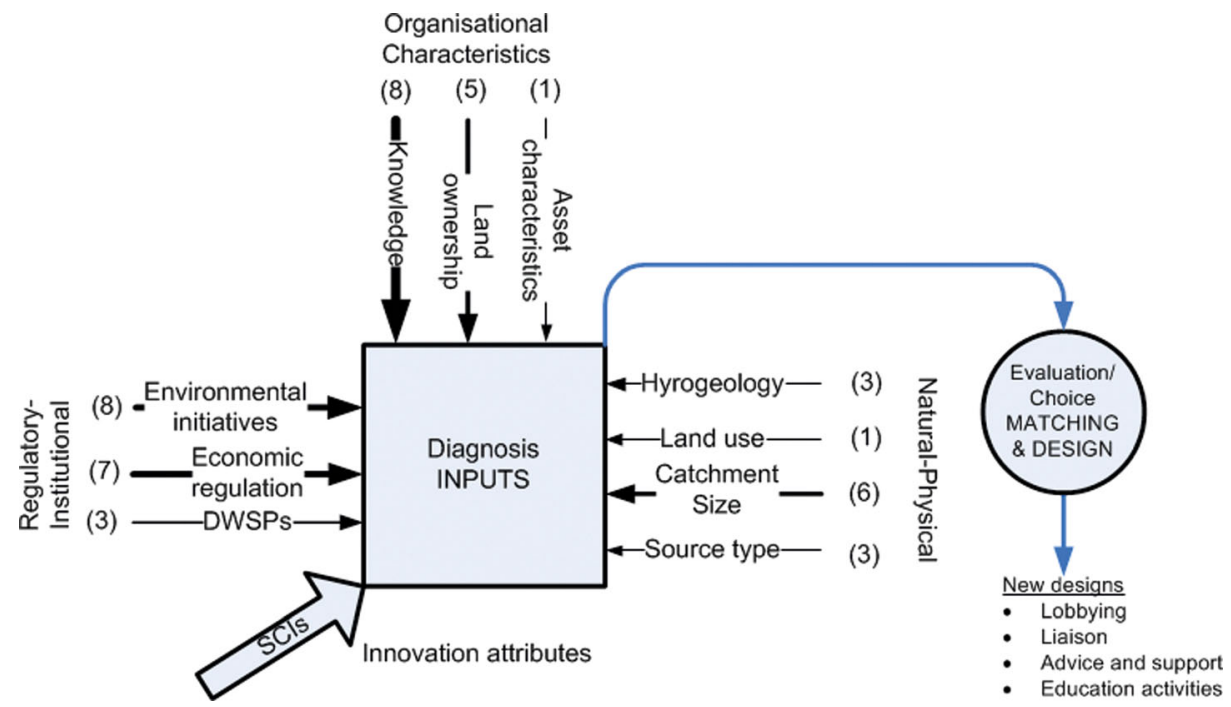

Fig. 4 The 'Re-innovation'/ 'Restructuring' process and the factors of influence (recurrence of factor displayed in brackets after arrow; 10 is the highest score possible due to sample size of 10 water utilities) 
Box 1 Explanation of the factors found to affect the innovation process.

\section{Regulation and Institutional Factors}

Drinking water quality standard (DWQS). The minimum quality standard for drinking water defined by the EC (EC 1998).

Drinking water safety plans (DWSPS). A multi barrier approach - from catchment to tap - to ensure potable water delivery (WHO 2005).

Water Framework Directive. EU legislation as adopted by E\&W (EC 2000).

Economic regulation. The price water utilities in $\mathrm{E} \& \mathrm{~W}$ can charge to customers is determined by economic regulation (Allan 2006).

Strategic Direction Statements. Water utilities are periodically required to published their business objectives for the next 25 year in Strategic Direction Statements (Ofwat 2009).

Environmental Initiatives. Governmental and voluntary schemes that aim to reduce agricultural water pollution in E\&W (Dolan et al. 2012).

Farmer participation. Participation of farmers is crucial for the success of SCIs requirements (Brouwer et al. 2003).

\section{Natural physical}

Trends and Peaks. This includes the rate and variability of water quality improvement or deterioration, including short term (seasonal) peaks.

Hydrogeology, water source and catchment size. The properties of an aquifer water source, whether the water source is groundwater or surface water, catchment size - in terms of $\mathrm{km}^{2}$ or the extent to which farmers have a stake (Spiller et al. 2009).

Land use. The type of agricultural land, peat land or urban land (Spiller et al. 2009).

\section{Organisational characteristics}

Land ownership. Whether the raw water catchment is owned by the water utilities.

Catchment and agricultural knowledge. Whether a water utility had already experience or knowledge in land management (Brouwer et al. 2003).

Asset characteristics. Whether water treatment technologies were currently able to meet the DWQS and whether it was anticipated that they would fail this standard in the future. This factor also includes costs of operating the assets and costs of construction of new assets.

Managerial attitudes. The way managers frame environmental problems and solutions (Sharma 2000).

Customer preference. Whether customers give preference to pollution prevention rather than end of pipe treatment (Brouwer et al. 2003).

\section{Innovation attributes}

Uncertainty. SCIs are associated with a risk of failing legal requirements, as quality improvements cannot be guaranteed (Brouwer et al. 2003).

Risk reduction. SCIs can mitigate operational risks - lower likelihood of contamination or investment in the future e.g. reduction of Cryptosporidium risk in the catchment, reversal of nitrogen pollution to groundwater (Spiller et al. 2013b).

Delayed response. Achieving water quality improvements with SCIs can take several years or decades (Brouwer et al. 2003).

Low costs of entry and operation. SCIs are perceived as being less costly than competing end of pipe treatment alternatives (Spiller et al. 2013b).

Low $\mathrm{CO}_{2}$ footprint. SCIs are argued to be less greenhouse gas emission intensive than treatment solutions.

\subsection{Agenda Setting - Performance gap and Direct Regulation}

Two ways exist to trigger innovation. Firstly, specific and concrete performance targets set aspiration levels that the organisation has to work towards. Secondly, regulation which requires water utilities to gather information about their own performance also raises awareness of a performance gap. Both mechanisms rely on a combination of factors from the domains of 
'Regulatory-Institutional', 'Natural-Physical' environment and 'Organisational Characteristics' (Fig. 2).

The mechanism of agenda setting works as follows. Drinking Water Quality Standards (DWQS) serve as a minimum target to be attained (6 out of 10 utilities - Fig. 2). More specifically, where treatment assets cannot mitigate raw water quality below the DWQS, a 'problem' is perceived. This is most likely where trends and peaks occur rather than where deteriorated raw water quality persists for some time. All 10 utilities mentioned these asset characteristics in relation to trends and peaks, simply because water treatment assets are often not designed to remove peak pollution loads or new pollutants (Dolan et al. 2014).

A similar way for 'Agenda Setting' to occur was indicated by one utility. This utility has to ensure adequate status of their land holdings since owning land brings the responsibility to maintain prescribed environmental objectives (i.e. Habitats Directive EC 1992). In this situation, the same elements as above can be identified, namely an aspiration level (i.e. the prescribed objective associated with land ownership), and the deviation or threat of deviation from this aspiration level (i.e. environmental status).

An alternative and frequent pathway to 'Agenda Setting' is related to the drinking water safety plans (DWSPs) (6). These require water utilities to map and assess the risks to raw water quality pollution arising from the catchment. As a result utilities build up an awareness of potential risks. This finding provides evidence for Porter and van der Linde's (1995) hypothesis that regulation which requires information gathering can have a positive effect on organisational innovation.

It is shown that direct regulation through DWQS and prescribed environmental objectives associated with land holdings performs well in initiating the innovation decision process. It is also evident that the Water Framework Directive (WFD) and economic regulation fail to do so. The WFD is not perceived as setting specific targets. Rather, it sets broad aspirations that challenge the present view of utilities' about how to deliver water services. This perception of the WFD does not suffice to initiate the innovation decision process itself but, as will be argued in the next section, has a crucial effect on the 'Choice between Alternatives'.

Like the WFD, there is a lack of evidence to confirm that economic regulation of water utilities is a trigger for innovation through stimulating the identification of a performance gap (Fig. 2). The interview findings, as well as other literatures (Barrett and Wallace 2011; Lieberherr and Truffer 2014) suggest that the regulatory demand for economic efficiency is inhibiting more rapid asset renewal (investment), thus limiting the break-up of old structures and, as a result, enforcing maintenance of incumbent technologies. In addition, the infrastructure of the sector with multi-million pound assets and replacement periods in the range of decades leads to a situation in which the replacement of assets that are operationally sound is often delayed (Brint et al. 2009; Marlow et al. 2013). This suggests that utilities will more likely look for opportunities to implement innovations at sites where assets need replacement because they near the end of their useful life or fail to meet statutory standards.

If the proposition holds true then it is suggested that the rate of innovation for water utilities in E\&W can only be influenced positively if one of the following situations occur:

- asset lifetimes are shortened,

- drinking water standards are tightened or customers make demands to exceed the drinking water standard (as for instance in Germany (Brouwer et al. 2003)),

- or the raw water quality is deteriorating. 


\subsection{Choice Between Alternatives - Matching and Aligning Factors}

Following the decision to innovate, a 'Choice between Alternatives' including option generation takes place - i.e. diagnosis of options (Fig. 3). A specific set of options (i.e. SCIs), sometimes termed the 'option space', is only considered when factors from all four domains are in alignment. Utilities select a 'SCIs option space' when the natural-physical characteristic of the catchment indicate a successful intervention (small catchments are preferred - 7) and their hydrogeology and source type (e.g. no large scale river catchments) should be suitable for comparatively quick success (3). However, they only do so when these conditions are matched with the 'right' customer preferences (3), managerial attitudes (6), asset characteristics (e.g. investment needs 8 ) or land ownership (5). Furthermore, an institutional enabling environment in terms of:

- $\quad$ support for SCIs by economic regulation (7),

- the legal requirement to protect drinking water at source i.e. Article 7 of the WFD (6) and the DWSPs (5),

- short term action in a long term framework (i.e. SDS - 5) and,

- the existence of agri-environmental initiatives (3) are also required.

If the alternatives meet these 'primary' enabling criteria, the innovation is examined for risks and benefits including uncertainty (8), $\mathrm{CO}_{2}$ emissions (5), cost efficiency (8) and water resource protection (5). This could be interpreted as a situation where utilities first of all aim to satisfy their basic statutory duties and only then will they consider long term goals and environmental objectives.

These findings confirm the proposition by Marlow et al. (2013), who argue that the option space of innovations is defined by the innovation actors' attitudes, characteristics of the innovation and drivers - including regulations. They further argue that everything in this option space must be a 'real' solution to a problem. Indeed, our findings confirm this, as they indicate that during the 'Choice between Alternatives' the attributes of the innovation must indicate that the problem identified in the 'Agenda Setting' process could be resolved by the alternative to be chosen, including achieving statutory drinking water objectives and conservation targets.

\subsection{Re-Innovation and Restructuring - Matching and Design}

The key difference of this stage to the 'Choice between Alternatives' is that innovation attributes are outcomes of the process rather than inputs (Fig. 4). Specifically, at this stage the utilities adapt the design of SCIs to fit 'Natural-Physical' characteristics, the 'RegulatoryInstitutional' conditions and 'Organisational Characteristics'. Four types of activities associated with re-innovated SCIs can be identified in this case study (Spiller et al. 2013a):

- Lobbying -to influence policy development to better protect drinking water resources,

- Liaison -built around influence and collaboration with intermediary organisations,

- Advice and support -the provision of technical advice and financial support directly to farmers,

- Education activities -water utilities directly engage with farmers with a focus on raising awareness on water quality issues.

Factors that influence the generation or design of these activities are environmental initiatives in the catchment (8); where they already exist water utilities design their SCIs as 
a liaison activity together with them. On the contrary, where environmental initiatives do not exist, water utilities have to develop advice and support SCIs since they cannot rely on the contacts and knowledge of other parties. Existing agricultural knowledge within the water utility is another important factor in the design of SCIs (8). Organisations that own land (5) and have therefore experience in land management are more likely to be actively involved in catchment management. These findings confirm that knowledge is crucial for innovation and more specifically that access to agricultural knowledge of water suppliers can be critical for catchment management (Spiller et al. 2013b; Dolan et al. 2014).

At the time of interviewing, economic regulation (7) did not permit the funding of direct payment to farmers, as this violates the polluter pays principle. As a consequence Liaison SCIs were most frequently used (8), while Advice and Support activities (5) could only be applied when utilities owned land or under special agreements with the regulator (Spiller et al. 2013a). Finally, utilities sought a lobbying or liaison approach in catchments with larger areas of surface water (source type - 3), because the catchment were perceived as too large and complex for active intervention. Contrary to this water utilities are actively involved in smaller catchments, especially if the river catchments are small or the aquifers show quick responses to land management change (hydrogeology - 3).

\subsection{Diffusion - Iteration of the Adoption Process}

In a few cases (3) there is evidence of factors that support the intra-organisational 'Diffusion' of innovations. These are situations where SCIs from one drinking water catchment are applied to another. The limited evidence indicates that 'Diffusion' is an iteration of the first three stages in the innovation process. It appears that when water utilities diffuse SCIs, they go through a process similar to the one described so far, with elements of 'Agenda Setting', 'Choice between Alternatives' and 'Re-innovation'.

If diffusion is indeed an iteration of the previous three stages then there is limited opportunity for policy to directly influence the spread of innovation. Rather, policy makers must create an enabling environment that stimulates innovation, leading to initial choices of innovation alternatives and then to appropriate re-innovation. Niches for learning, experimentation and consequently further adoption are likely to be important in this context (Brugge and Rotmans 2007). A key challenge is to find the right balance between direct regulation, which is more likely to trigger reactive innovation, and flexible regulation, which appears to perform better in allowing utilities to be responsive and to choose and design innovation alternatives.

\section{Conclusions}

This paper has demonstrated how a description of innovation as a process combined with an understanding of factors that influences that process can be helpful in identifying:

I. how to foster initiation of innovations,

II. how to influence the choice for specific innovations,

III. how to encourage a wider diffusion of innovations within and across organisations.

I. Results suggest that direct regulation in terms of drinking water or environmental standards performs best in stimulating the innovation process. Furthermore, regulation that requires information gathering (i.e. Drinking Water Safety Plans) can have a similar effect if it leads to the identification of a performance gap. The identification of 
a performance gap is dependent on the asset characteristics and the state of the naturalphysical environment. Triggering innovation in water utilities is therefore context specific. The research cannot confirm that encouraging economic efficiency of privatised water utilities will deliver innovation and change. Likewise, there is no evidence that the WFD stimulates a higher rate of innovation.

II. Whilst economic regulation and the WFD may not trigger innovation they do alter the character of the innovation, that is, the type of innovation an organisation may choose. There is evidence that flexible regulations or framework directives (e.g. Drinking Water Safety Plans, WFD) can be employed to guide change into the desired direction, for instance by encouraging the choice of more risky managerial solutions such as SCIs, rather than proven technological solutions, to meet defined standards. The adaptation of innovations to specific organisational and environmental circumstances is crucial for successful implementation. What influences this process are the institutional environment, relevant organisational knowledge and natural physical factors.

III. There is limited evidence about the factors that affect diffusion. It appears that this stage is essentially an iteration of the three previous innovation stages. This topic should be investigated further as it implies that if policy makers want to stimulate the diffusion of innovations within water utilities they need to focus on developing policies that address these three stages.

Acknowledgments The authors would like to acknowledge the support of the EC funded ISBP project (NESTPATHFINDER-CUL 043199, Integrated Systems and the Boundary Problem) and the kind co-operation of all interviewees.

Open Access This article is distributed under the terms of the Creative Commons Attribution License which permits any use, distribution, and reproduction in any medium, provided the original author(s) and the source are credited.

\section{References}

Allan G (2006) Assessing capital efficiency in the water and sewerage industry in England and Wales: Ofwat's approach. Util Policy 14:224-233

Barrett G, Wallace M (2011) An institutional economics perspective: the impact of water provider privatisation on water conservation in England and Australia. Water Resour Manag 25:1325-1340

Brint A, Bridgeman J, Black M (2009) The rise, current position and future direction of asset management in utility industries. J Oper Res Soc 60:106-113

Brouwer F, Heinz I, Zabel T (2003) Occurrence of co-operative agreements. In: Brouwer F, Heinz I, Zabel T (eds) Governance of water-related conflicts in agriculture, vol 37, New directions in agri-environmental and water policies in the EU. Kluwer Academic Publishers, London, pp 23-44

Brown R, Farrelly M (2009) Delivering sustainable urban water management: a review of the hurdles we face. Water Sci Technol 59:839

Brugge R, Rotmans J (2007) Towards transition management of European water resources. Water Resour Manag 21:249-267. doi:10.1007/s11269-006-9052-0

Burns T, Stalker GM (1968) The management of innovation, 2nd edn. Travistock Publications, London

Buysse K, Verbeke A (2003) Proactive environmental strategies: a stakeholder management perspective. Strategic Manage J 24:453-470

Cashman A, Lewis L (2007) Topping up or watering down? Sustainable development in the privatized UK water industry. Bus Strat Environ 16:93-105

Cave M (2009) Independent Review of Competition and Innovation in Water Markets: Final report. DEFRA. https://www.gov.uk/government/uploads/system/uploads/attachment_data/file/69462/cave-review-finalreport.pdf. Accessed 20 Nov 2014 
Cleff T, Rennings K (1999) Determinants of environmental product and process innovation. Eur Environ 9:191201

Cohen WM, Levinthal DA (1990) Absorptive capacity: a new perspective on learning and innovation. Admin Sci Quart 35:128-152

Daigger GT (2012) A Vision for Urban Water and Wastewater Management in 2050. In: Grayman WM, Loucks DP, Saito L (eds) Toward a Sustainable Water Future. American Socienty of Civil Engineers, pp 166-174. doi:10.1061/9780784412077.fm

del Rio Gonzalez P (2009) The empirical analysis of the determinants for environmental technological change: a research agenda. Ecol Econ 68:861-878

Dolan T, Howsam P, Parsons DJ (2012) Diffuse pesticide pollution of drinking water sources: impact of legislation and UK responses. Water Policy 14:680-693

Dolan T, Parsons D, Howsam P, Whelan M, Varga L (2014) Identifying adaptation options and constraints: the role of agronomist knowledge in catchment management strategy. Water Resour Manag 28:511-526. doi:10. 1007/s11269-013-0498-6

Du J, Love JH, Roper S (2007) The innovation decision: an economic analysis. Technovation 27:766-773

EC (1992) Council Directive 92/43/EEC of 21 May 1992 on the conservation of natural habitats and of wild fauna and flora European Commission, Brussels

EC (1998) Council Directive 98/83/EC of 3 November 1998 on the quality of water intended for human consumption

EC (2000) Council Directive 2000/60/EC of the European Parliament and of the Council. Establishing a framework for community action in the field of water policy. European Commission

Georg S (1994) Regulating the environment: changing from constraint to gentle coercion. Bus Strat Environ 3: 11-20

Harrison K (1998) Talking with the Donkey: cooperative approaches to environmental protection. J Ind Ecol 2: 51-72. doi:10.1162/jiec.1998.2.3.51

Heerkens H (2006) Assessing the importance of factors determining decision-making by actors involved in innovation processes. Creat Innov Manag 15:385

Horbach J (2008) Determinants of environmental innovation: new evidence from German panel data sources. Res Pol 37:163-173

Karakaya E, Hidalgo A, Nuur C (2014) Diffusion of eco-innovations: a review. Renew Sustainable Energy Rev 33:392-399

Kujawa-Roeleveld K, Zeeman G (2006) Anaerobic treatment in decentralised and source-separation-based sanitation concepts. Rev Environ Sci and Biotechnol 5:115-139

Lieberherr E, Truffer B (2014) The impact of privatization on sustainability transitions: A comparative analysis of dynamic capabilities in three water utilities. Environmental Innovation and Societal Transitions

Majumdar SK, Marcus AA (2001) Rules versus discretion: the productivity consequences of flexible regulation. Acad Manage J 44:170-179. doi:10.2307/3069344

Maria L (2005) EU environmental Law. Challenges, change and decision making. Hart Publishing, Portland

Marlow DR, Moglia M, Cook S, Beale DJ (2013) Towards sustainable urban water management: a critical reassessment. Water Res 47:7150-7161

Miles M, Huberman A (1994) Qualitative data analysis: an expanded sourcebook. Sage, Pubns

Mintzberg H, Raisinghani D (1976) The structure of 'unstructured' decision processes. Admin Sci Quart 21:246275

Ofwat (2009) Strategic Direction Statements. http://www.ofwat.gov.uk/pricereview/sds/. Accessed 20 Nov 2014

Ormrod R (1990) Local context and innovation diffusion in a well-connected world. J Econ Geogr 66:109-122

Porter ME, van der Linde C (1995) Toward a new conception of the environment-competitiveness relationship. J Econ Perspect 9:97-118

Rogers EM (2003) Diffusion of innovation, 5th edn. Free Press, London

Romano G, Salvati N, Guerrini A (2014) Factors affecting water utility Companies' decision to promote the reduction of household water consumption. Water Resour Manage 28:5491-5505. doi:10.1007/s11269-0140818-5

Rothwell R (1992) Successful industrial innovation: critical factors for the 1990s. R\&D Manag 22:221-239

Sharma S (2000) Managerial interpretations and organizational context as predictors of corporate choice of environmental strategy. Acad Manage J 43:681-697

Sharma S (2001) Different strokes: regulatory styles and environmental strategy in the North-American oil and gas industry. Bus Strat Environ 10:344-364. doi:10.1002/bse.303

Simon AH (1997) Administrative behavior. A study of decision-making processes in administrative organisations. The Free Press, New York

Spiller M, McIntosh B, Seaton R (2009) The influence of supply and sewerage area characteristics on water and sewerage companies responses to the water framework directive. Water Sci Tech 60:1811 
Spiller M, McIntosh BS, Seaton RAF, Jeffrey PJ (2012) An organisational innovation perspective on change in water and wastewater systems-the implementation of the water framework directive in England and Wales. Urban Water J 9:113-128

Spiller M, McIntosh BS, Seaton RA, Jeffrey P (2013a) Implementing pollution source control-learning from the innovation process in english and welsh water companies. Water Resour Manag 27:75-94

Spiller M, McIntosh BS, Seaton RAF, Jeffrey P (2013b) Pollution source control by water utilities - characterisation and implications for water management: research results from England and Wales. Water Environ $\mathrm{J}$ 27:177-186. doi:10.1111/j.1747-6593.2012.00340.x

Spiller M, Vreeburg JHG, Leusbrock I, Zeeman G (2015) Flexible design in water and wastewater engineering definitions, literature and decision guide. J Env Manag 149:271-281. doi:10.1016/j.jenvman.2014.09.031

Strauss AL, Corbin JM (1998) Basics of qualitative research. Techniques and procedures for developing grounded theory. SAGE Publications, London

Teece DJ, Pisano G, Shuen A (1997) Dynamic capabilities and strategic management. Strategic Management J 18:509-533

Thomas AD, Ford RR (2005) The crisis of innovation in water and wastewater. Edward Elgar Publishing Limited, UK

Verstraete W, Vlaeminck SE (2011) ZeroWasteWater: short-cycling of wastewater resources for sustainable cities of the future. Int J Sust Dev World 18:253-264

WHO (2005) Water safety plans: Managing drinking-water quality from catchment to consumer. http://www. who.int/water_sanitation_health/dwq/wsp0506/en/index.html. Accessed 18 Oct 2014 